\title{
KNEE CAP: A MORPHOMETRIC STUDY
}

\section{Magi Murugan *, Sri Ambika, Virendar Kumar Nim.}

Department of Anatomy, Pondicherry Institute Of Medical Sciences, Pondicherry, India.

\section{ABSTRACT}

Background: The patella is the largest sessamoid bone embedded in the tendon of quadriceps femoris. Patella although not distinct for determining sex or race it is used for personal identification as it is resistant to post mortem changes.

Purpose of the study: Dimensions and classification of patellae are important anthropologically as well as clinically for the determination of the size of a patellar implant. Since there has been no previous morphometric study on the patellae in South India population, this study aims at giving dimensions on measurements of patella as well as to classify them based on the articular facets.

Results: A total of 65 dry right and left patella of both sexes were examined using five measurements. In this study the mean height, width and thickness of patella were $38.07,38.58$, and $18.29 \mathrm{~mm}$ respectively.

Conclusion: The patellar height is of fundamental importance for patellofemoral operations involving knee arthroplasty, anterior cruciate ligament or proximal tibial osteotomy. Morphometric data presented in this study is beneficial for orthopedicians in designing patellar implants for procedures involving knee.

KEY WORDS: Patella, Articular facet, Morphometry, South Indian Population.

Address for Correspondence: Dr.Magi Murugan, Associate Professor, Department of Anatomy. Pondicherry Institute Of Medical Sciences, Pondicherry, India.

E-Mail: magimurugan_78@yahoo.com

\section{Access this Article online}

\section{Quick Response code}

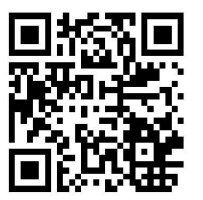

DOI: $10.16965 /$ ijar.2016.451

Web site: International Journal of Anatomy and Research ISSN 2321-4287 www.ijmhr.org/ijar.htm

Received: 25 Oct 2016

Peer Review: 25 Oct 2016

Revised: 08 Dec 2016
Accepted: 24 Feb 2017

Published (O): 31 Mar 2017

Published (P): 31 Mar 2017

\section{INTRODUCTION}

The patella is the largest sessamoid bone and is embedded in the tendon of quadriceps femoris, anterior to the femoral condyles. It is flat, distally tapered, proximally curved, and has anterior and posterior surfaces, three borders and an apex which is the distal end of the bone. The subcutaneous, convex anterior surface is longitudinally ridged, separated from the skin by a prepatellar bursa, and covered by an expansion from the tendon of quadriceps femoris. The posterior surface has a proximal smooth, oval articular area, crossed by a smooth vertical ridge, which fits the intercondylar groove on the femoral patellar surface and divides the patellar articular area into medial and lateral facets; the lateral is usually larger. Each facet is divided by faint horizontal lines into equal thirds. Distal to the articular surface, the apex is roughened by the attachment of the patellar tendon. The articular cartilage is the thickest in the body, reflecting the magnitude of the stresses to which it is subjected. The thick superior border slopes anteroinferiorly. The medial and lateral borders are thinner and converge distally. The shape of the patella can vary, and certain configurations are associated with patellar instability [1].

The knee cap (patella) although does not have any distinct morphological features for determining sex or race but still it is used for 
personal identification purposes as it is resistant to post-mortem changes [2]. Dimensions and classification of patellae are important anthropologically as well as clinically for the determination of the size of a patellar implant [3]. A disproportional implant of the patellofemoral joint would result in an ineffective lever support, limitation of motion, excessive wear and instability of the patella with associated knee pain [4].

Wiberg categorised patella into 3 types based on the dimensions of the widths of medial (MAF) and lateral articular facets (LAF) as well as the curvature of the facets. Type I patella is defined as a patella whose MAF and LAF widths are concave and equal. Type II patella is one in which the width of the MAF is flat or slightly convex and smaller than the width of the LAF. In Type III patella the width of the MAF is convex and considerably smaller than the width of the LAF [5]. In another study on the classification of the patellae of foetal cadavers, Koyuncu et al. reported that $20 \%$ of patellae was Class $A$ (the widths of MAF and LAF are equal). In Class $B$ (the width of the MAF is smaller than the width of the LAF) was reported as the most prevalent (50\%) while $30 \%$ of patellae were Class C (the width of MAF was greater than the width of the LAF [3]. Since there has been no previous morphometric study on the patellae in South India population, this study aims at giving certain dimensions on measurements of patella as well as to classify them based on the articular facets.

\section{MATERIALS AND METHODS}

The study consists of 65 dry right and left patella of both sexes procured from department of Anatomy,Pondicherry Institute of Medical sciences, Pondicherry. Specimens with signs of fracture, pins and plates, bad erosion or loss of bone density were excluded from the study. Measurements of patella namely patella height, width, thickness, width of the medial articular facet and lateral articular facet were, measured using sliding vernier calliper. Table I shows the description of measurements taken on patella.

Statistical Analysis: Student t-test was used to ascertain whether significant difference existed between the right and left patella. The mean, maximum, minimum and standard deviation was calculated and tabulated.

Tablel 1: Description of measurements taken on patella.

\begin{tabular}{|c|c|c|}
\hline Measurements & Abbreviation & Description \\
\hline Patella Height & PH & $\begin{array}{c}\text { Linear distance between superior } \\
\text { border and apex }\end{array}$ \\
\hline Patella width & PW & $\begin{array}{c}\text { Linear distance between medial and } \\
\text { lateral border }\end{array}$ \\
\hline Patella thickness & PT & $\begin{array}{c}\text { Linear distance between anterior } \\
\text { surface and median ridge on } \\
\text { posterior surface }\end{array}$ \\
\hline $\begin{array}{c}\text { Width of medial } \\
\text { articular facet }\end{array}$ & WMAF & $\begin{array}{c}\text { Maximum width from the medial } \\
\text { border to the median ridge }\end{array}$ \\
\hline $\begin{array}{c}\text { Width of lateral } \\
\text { articular facet }\end{array}$ & WLAF & $\begin{array}{c}\text { Maximum width from the lateral } \\
\text { border to the median ridge }\end{array}$ \\
\hline
\end{tabular}

\section{RESULTS}

The results of descriptive statistical analysis were reported in Table II showing the mean, maximum, minimum and standard deviation (SD) of right and left side for both the sexes.

Table 2: Descriptive statistics of measurements of patella.

\begin{tabular}{|c|c|c|c|c|}
\hline Measurements & Mean & Maximum & Minimum & $\begin{array}{c}\text { Standard } \\
\text { deviation }\end{array}$ \\
\hline Patella Height & 38.07 & 45.77 & 31.59 & 3.79 \\
\hline Patella width & 38.58 & 47.52 & 31.15 & 3.81 \\
\hline Patella thickness & 18.29 & 21.63 & 14.05 & 1.73 \\
\hline $\begin{array}{c}\text { Width of medial } \\
\text { articular facet }\end{array}$ & 22.75 & 29.21 & 18.27 & 2.66 \\
\hline $\begin{array}{c}\text { Width of lateral } \\
\text { articular facet }\end{array}$ & 18.78 & 24.64 & 15.24 & 1.95 \\
\hline
\end{tabular}

The results of Student $t$ test reported in table III revealed that there was no significant difference between the right and left side of patella.

Table 3: Comparison between the measurements of the right and left patella using student's t-test.

\begin{tabular}{|c|c|c|}
\hline Measurements & $\mathrm{t}$-value & $\mathrm{p}$-value \\
\hline Patella Height & 0.23 & 0.81 \\
\hline Patella width & 0.13 & 0.89 \\
\hline Patella thickness & 0.11 & 0.91 \\
\hline $\begin{array}{c}\text { Width of medial } \\
\text { articular facet }\end{array}$ & 0.28 & 0.78 \\
\hline $\begin{array}{c}\text { Width of lateral } \\
\text { articular facet }\end{array}$ & 0.97 & 0.33 \\
\hline
\end{tabular}

Classification of patella according to Koyuncu's classification was reported in table IV. Most of the patella in the studied sample was classified as class $B$. Of the 65 samples studied 58 were class $B$ and 7 were class $A$.

Table 4: Koyuncu's classification of patella.

\begin{tabular}{|c|c|}
\hline Class & Number of patella(\%) \\
\hline A & $7(10.8 \%)$ \\
\hline B & $58(89.2 \%)$ \\
\hline C & $0(0 \%)$ \\
\hline
\end{tabular}


Table 5: Statistical analysis of $\mathrm{w} / \mathrm{t}$ ratio and wlaf/ wmaf ratio.

\begin{tabular}{|c|c|c|}
\hline Items & W/T & WLAF/WMAF \\
\hline Mean & 2.11 & 1.21 \\
\hline S/D & 0.19 & 0.11 \\
\hline
\end{tabular}

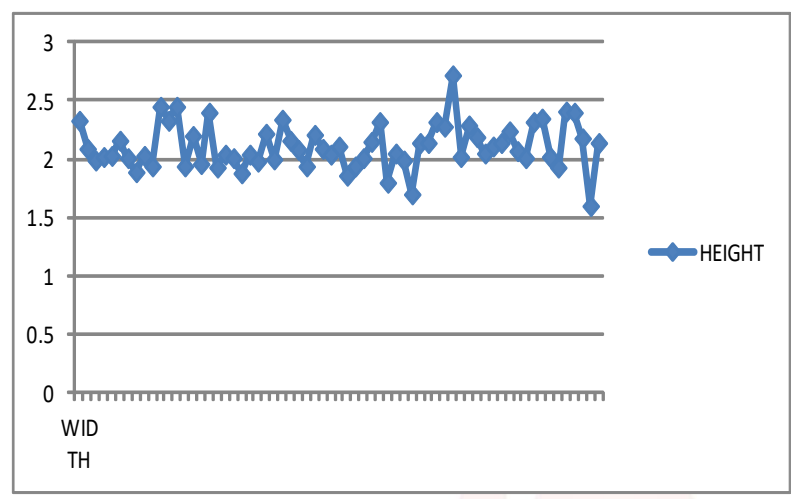

\section{DISCUSSION}

The patella is an important component in the extensor mechanism of knee joint. It increases the efficiency of quadriceps muscle by acting as a lever ${ }^{6}$. In the present study the mean height, width and thickness of patella were $38.07,38.58$, and $18.29 \mathrm{~mm}$ respectively. The data obtained from this study were compared with those from previous studies as summarised in Table 6.

In the present study mean width of the patella was $38.58 \mathrm{~mm}$ and standard deviation was 3.81, which was less compared to that of the previous study by Shang Peng et al in 2014 where the width was $44.13 \mathrm{~mm}$ and standard deviation was 3.96. Previously in a study by Oladrian 2013 in morphometric analysis of patella of South Africans the width was $45.14 \mathrm{~mm}$ which was high compared to the present study. Although the reasons for these variations cannot be validated but the differences may be due to the difference in methods of measuring, age, sexes, race and stature [12].

Table 6: Summary of studies which report patella dimensions.

\begin{tabular}{|c|c|c|c|c|c|c|}
\hline \multirow{8}{*}{$\begin{array}{l}\text { Table 6: Summary of } \\
\text { studies which report } \\
\text { patella dimensions. }\end{array}$} & \multirow[t]{2}{*}{ Study } & \multirow[t]{2}{*}{ Sample and subjects } & \multicolumn{2}{|c|}{ Patella height } & \multicolumn{2}{|c|}{ Patella thickness } \\
\hline & & & Mean & SD & Mean & SD \\
\hline & Yoo et al 2007 [7] & $\begin{array}{l}\text { Magnetic resonance imaging } \\
\text { measurements of } 163 \text { adults }\end{array}$ & 44.6 & 3.7 & 22.3 & 1.9 \\
\hline & Schlenzka and Schwesinger 2014 [8] & $\begin{array}{c}50 \text { fresh human adult cadaveric } \\
\text { patellae }\end{array}$ & 54.4 & 3.5 & & \\
\hline & Iranpour et al 2008 [9] & $\begin{array}{c}\text { 3D reconstructed CT scans from } 37 \\
\text { adults }\end{array}$ & 34.3 & 4.8 & 22.4 & 2.3 \\
\hline & Baldwin and House 2005 [10] & $\begin{array}{c}92 \text { adult patella during total knee } \\
\text { arthroplasty } \\
\end{array}$ & & & 22.6 & \\
\hline & Shang Peng 2014 [11] & CT scan from 40 Chinese volunteers & 39.94 & 3.68 & 22.72 & 1.81 \\
\hline & Present study & 65 adult dry patella & 38.07 & 3.7 & 18.29 & 1.73 \\
\hline
\end{tabular}

In the present study the width of the medial articular facet was $18.78 \mathrm{~mm}$ which was similar to the studies done on other populations like Chinese, Koreans and Westerners in whom the values were $19.03 \mathrm{~mm}, 18.4 \mathrm{~mm}$ and $18.8 \mathrm{~mm}$ respectively. Similarly the width of the lateral

values were $19.03 \mathrm{~mm}, 18.4 \mathrm{~mm}$ and $18.8 \mathrm{~mm}$ respectively. Similarly the width of the lateral articular facet in our study was $22.75 \mathrm{~mm}$ and $25.1 \mathrm{~mm}$ in Chinese, $23.3 \mathrm{~mm}$ in Koreans and $25.3 \mathrm{~mm}$ in Westerners respectively [13].

The ratio of width to the thickness of patella was $2.11 \mathrm{~mm}$ and SD 0.19 which was similar to the studies in UK population with an average value of $2.1 \mathrm{~mm}$. In the studies done on Chinese the width to the thickness ratio was 1.94 (SD 0.12 , range $1.66-2.20$ ), which was less than that of the present study. The patella thickness to width ratio is also a reliable predictive factor to decide on the thickness of the patella prosthesis during arthroplasty. (Iranpour 2008) The ratio of the lateral facet to medial facet was 1.21 which was similar to the study done by Shang Peng 1.33 (SD 0.18, range 0.91-1.71).

In the present study, there was no significant difference in the right and left sides of patella which was similar to that of the study by Olandrian. Patellae were also classified based on the dimensions of the articular facets. In the present study, it was found that the Type B patella was the most prevalent, which is in support of previous observations by Fucentese et al [14]. The patellar height is of fundamental operations involving knee arthroplasty, anterior cruciate ligament or proximal tibial osteotomy [15]. These morphometric measurements can be used in forensic department for sex determination with highest accuracy rate [2]. importance for patellofemoral complaints, 


\section{CONCLUSION}

We suggest that morphometric data presented in this study is beneficial for orthopedicians in designing patellar implants for procedures involving knee.

\section{Conflicts of Interests: None}

\section{REFERENCES}

[1]. Standring, S. Pelvic Girdle and lower limb', in Mahadevan V 40 $0^{\text {th }}$ (ed.) Gray's Anatomy - Anatomical Basis of Clinical Practice. Newyork: Elsevier Churchill Livingstone, 2008;1349.

[2]. Paolo Phoophalee, Sukon Prasitwattanaseree, Suda, R., Pasuk, M. (2012) 'Sex Determination by Patella Measurements in Thais', AGRC Forensic science Graduate Program, 2012;472-477.

[3]. Koyuncu, E., Cankara, N., Sulak, O., Ozguner, G., Albay, S. The morphometry of patella and patellar ligament during the fetal period. Clin Anat, 2011;24:225-231.

[4]. Iranpour, F., Merican, AM.,Cobb, JP., Amis, AA. The width : thickness ratio of the patella: An aid in knee arthroplasty. Clin Orthop Relat Res, 2008;466:11981203.

[5]. Wiberg, G. Roentgenographic and anatomic studies on the femoropatellar joint. acta Orthop scand. 1941;12:319-410.

[6]. Sachin Upadhyay, HKT Raza, Pranay Srivastava. Position of the patella in adults in central India: Evaluation of the Insall-Salvati ratio. Journal of Orthopaedic Surgery, 2013;21(1):23-7.

[7]. Yoo JH, Yi SR, Kim JH. The geometry of patella and patellar tendon measured on knee MRI. Surg Radiol Anat. 2007;29:623-266.

[8]. Schlenzka D, Schwesinger G. The height of the patella: An anatomical study. E J Radiol. 1990;11:1921.
[9]. Iranpour F, Merican AM, Cobb JP, Amis AA. The width:thickness ratio of the patella: An aid in knee arthroplasty. Clin Orthop Relat Res. 2008;466:11981203.

[10]. Baldwin JL, House K. Anatomical dimensions of the patella measured during total knee arthroplasty. J Arthroplasty. 2005;20:250-257.

[11]. Shang Peng, Zhang Linan, Hou Zengtao, Bai Xueling, Ye Xin, Xu Zhaobin and Huang Xu. Morphometric measurement of the patella on $3 \mathrm{D}$ model reconstructed from CT scan images for the southern Chinese population Chin Med J 2014;127(1).

[12]. Olateju, OL., Philander, I., Bidmos, MA. Morphometric analysis of the patella and patellar ligament of South Africans of European ancestry. South African Journal of Science, 2013;109(9/10):1-5.

[13]. Shang Peng, Zhang Linan, Hou Zengtao, Bai Xueling, Ye Xin, Xu Zhaobin, et al. Morphometric measurements of the patella on 3D model reconstructed from CT scan images for the southern Chinese population. Chin Med J, 2014;127(1): 96-101.

[14]. Fucentese, SF., Von Roll, A., Koch, PP., Epari, DR., Fuchs, B., Schottle, PB. The Patellar morphology in trochlear dysplasia: A comparitive MRI study. Knee, 2006;13:145-150.

[15]. Christian, B., Alexandre, Z., Rodrigo, P., Eduardo, B., Naasson, C. Comparitive evaluation of patellar height methods in the Brazilian population. Revista Brasileira De Ortopedia, 2016;1(1):53-57.

How to cite this article:

Magi Murugan, Sri Ambika, Virendar Kumar Nim. KNEE CAP: A MORPHOMETRIC STUDY. Int J Anat Res 2017;5(1):3556-3559. DOI: $10.16965 /$ ijar.2016.451 